\title{
\begin{tabular}{l|l} 
pcori $).$ & PATIENT-CENTERED OUTCOMES RESEARCH INSTITUTE \\
RESEARCH SUMMARY
\end{tabular}
}

PROJECT INFORMATION

September 2018

\section{Testing Tablet-Based Software to Help Reduce Hospice Patients' Pain}

Principal investigator

Organization

Robert E. Molokie, MD

University of Illinois at Chicago

\section{What was the research about?}

Hospice care aims to keep patients comfortable and reduce their pain in the last weeks or months of life. In this study, the research team wanted to reduce pain for patients with cancer in hospice care. The team created PAINRelievelt, a software program for patients and their caregivers to use on a tablet. Caregivers are family members or friends who help a patient on a regular basis.

The PAINRelievelt program had three parts:

- Patients entered information about their pain and pain medicine.

- Patients and caregivers got information about how to manage pain.

- Nurses reviewed patients' entries to help manage patients' pain.

The research team compared patients who used PAINRelievelt as part of hospice care with patients who got regular hospice care only.

\section{What were the results?}

The study found no differences between patients who used PAINRelievelt and patients who got regular hospice care in

- How often patients took their pain medicine as prescribed

- How well patients understood how to manage pain
- How satisfied patients were with their pain levels

Caregivers who used PAINRelievelt understood more about how to manage pain than caregivers who didn't use the program.

\section{Who was in the study?}

The study included 234 patients with cancer getting care at home from two hospice services in Chicago. The research team expected all patients to live at least 10 days. Among patients, 49 percent were white, 35 percent were black, 14 percent were another race, and 18 percent were Hispanic. Patients' average age was 68 , and 51 percent were women.

The study also included 231 caregivers of patients in the study. The average age of caregivers was 53, and 74 percent were women. Among caregivers, 44 percent were white, 36 percent were black, 12 percent were another race, and 20 percent were Hispanic.

\section{What did the research team do?}

The research team assigned patients by chance to get either usual hospice care or hospice care plus the PAINRelievelt program. All patients had a tablet computer. They used the tablets to record information about their pain and pain medicine each day for six days.

Patients in the PAINRelievelt group and their caregivers could also learn how to manage pain on their tablet. Patients in the usual care group could play games on their tablet. 
Before and after the study, patients filled out surveys about their pain, and patients and caregivers filled out surveys about how to manage pain.

\section{What were the limits of the study?}

Because of changes to how the research team asked patients to take part in the study, more patients ended up getting usual hospice care than PAINRelievelt.

Results may differ in a study with similar numbers of patients in each study group. Nurses didn't always have access to patients' pain reports. This may have affected how they managed pain.
Future research could continue to look at ways to help patients in hospice care manage pain.

\section{How can people use the results?}

People who work in hospice care may use these results when deciding how to help patients and caregivers manage pain.

To learn more about this project, visit www.pcori.org/Molokie148. 